\title{
Probiótico em dietas de suínos sobre os parâmetros sanguíneos e digestibilidade de rações ${ }^{1}$
}

\author{
Probiotic in swine diets on the blood parameters and rations \\ digestibility
}

\author{
Rizal Alcides Robles-Huaynate²; Maria Cristina Thomaz; \\ Áureo Evangelista Santana3; Guido Carlos Iselda Hermans Masson²; \\ Alessandro Borges Amorim²; Susana Zaneti Silva4; Urbano do Santos Ruiz; \\ Pedro Henrique Watanabe ${ }^{2}$; Fábio Enrique Lemos Budiño ${ }^{5 *}$
}

\begin{abstract}
Resumo
Realizou-se dois ensaios, ambos utilizando delineamento em blocos casualizados, sendo o primeiro com o objetivo de avaliar os parâmetros sanguíneos de leitões recém desmamados, recebendo rações com e sem probiótico. Foram utilizados 20 leitões, com peso corporal de $6,99 \pm 0,42 \mathrm{~kg}$, sendo colhidas amostras de sangue, aos $0,7,14,21$ e 28 dias pós-desmame, para as determinações das concentrações de hemácias, hemoglobina, hematócrito, leucócitos, eosinófilos, neutrófilos bastonetes e segmentados, linfócitos, monócitos, plaquetas, proteínas séricas totais, albumina, globulina e alfa e beta+gama globulinas. No segundo ensaio determinou-se os coeficientes de digestibilidade, os nutrientes digestíveis e as energias digestível e metabolizável de rações, contendo ou não probióticos, para suínos na fase de crescimento. Observou-se que as rações e as idades dos animais influenciaram a maioria das variáveis sanguíneas e o probiótico não alterou a digestibilidade das rações, com exceção da disponibilidade da matéria mineral. Conclui-se que os parâmetros sanguíneos são alterados pelo uso do probiótico e pela idade dos animais, ambos ressaltados pelos desafios ocorridos após o desmame e a matéria mineral é melhor aproveitada com o uso do probiótico.
\end{abstract}

Palavras-chave: Bacillus spp., células sanguíneas, estresse, matéria mineral, suíno

\begin{abstract}
Two assays were accomplished being, both using a randomized block design: Assay 1 the aimed was to evaluate the blood parameters of weaned recently pigs and receiving rations with and without probiotic. Twenty pigs with body weight of $6.99 \pm 0.42 \mathrm{~kg}$ were used and were collected samples of blood to the $0,7,14,21$ and 28 days after wean, for determinations of the bool parameters. Assay 2 the objective was to determine the rations digestibility for growth swine supplemented or not with probiotic in the rations. The rations and the ages of the animals influenced most of the variables of the blood parameters.
\end{abstract}

\footnotetext{
${ }^{1}$ Parte da tese de doutorado do primeiro autor, Universidade Estadual Paulista "Julio de Mesquita Filho", FCAV/UNESP, Campus de Jaboticabal, Jaboticabal, SP.

${ }^{2}$ Discentes do Curso de Doutorado do Programa de Pós Graduação em Zootecnia, FCAV/UNESP, Campus de Jaboticabal, Jaboticabal, SP. E-mail: rizal3@hotmail.com; guidomasson@gmail.com; alessandrozoo@gmail.com; usruiz@yahoo.com.br; pedrowatanabe@cchsa.ufpb.br

${ }^{3}$ Profs. Drs. da FCAV/UNESP, Campus de Jaboticabal, Jaboticabal, SP. E-mail: thomaz@fcav.unesp.br; santana@fcav.unesp.br

${ }^{4}$ Discente de Graduação em Zootecnia da FCAV/UNESP, Campus de Jaboticabal, Jaboticabal, SP. E-mail: educazoo@hotmail. com.br

${ }^{5}$ Pesquisador Dr. do Instituto de Zootecnia, APTA/SAA, Nova Odessa, SP. E-mail: fbudino@iz.sp.gov.br

* Autor para correspondência
} 
The probiotic didn't alter the ration digestibility to exception for mineral matter. It is ended that the blood parameters were altered for the use of the probiotic and the age of the animals, both emphasized to challenges happened after wean and the mineral matter was better taken advantage with the use of the probiotic.

Key words: Bacillus spp., blood cells, mineral matter, stress, swine

\section{Introdução}

$\mathrm{O}$ uso de antibióticos como promotores de crescimento, permite melhorar o desempenho dos animais, mas está sendo banido da suinocultura, devido principalmente aos riscos representados pelas bactérias resistentes, que podem trazer problemas para as saúdes animal e humana (MONTAGNE; PLUSQUE; HAMPSON, 2003).

Por outro lado, os nutricionistas têm buscado novas alternativas visando atingir bons índices produtivos, e com base neste conceito surgiram os probióticos, que são suplementos microbianos vivos constituídos por bactérias, fungos ou leveduras, capazes de melhorar o equilíbrio microbiano no trato gastrintestinal, levando à consequente redução nos agentes patogênicos, além de estimular o sistema imunológico do hospedeiro (WALKER; DUFFY, 1998) e melhorar a digestibilidade da ração e a absorção de nutrientes (LEEDLE, 2000).

Os probióticos possuem ação na imunomodulação do hospedeiro, devido à produção de glicopeptídeos ou outros metabólitos. Também, mostrou-se o efeito nutricional dos probióticos mediante o estímulo à produção de enzimas como a lactase e pela manutenção saudável das vilosidades intestinais, as quais melhoram a digestibilidade de alimentos e a absorção de nutrientes (LAN et al., 2005).

O sangue é responsável pela oxigenação dos tecidos, transporte de nutrientes, produtos de excreção, hormônios, calor, anticorpos, e também pela defesa do organismo animal. Apresenta uma fase líquida, onde se dissolvem proteínas, açúcares, sais e íons, e uma parte sólida, formada por diferentes tipos celulares, representados por hemácias, leucócitos e plaquetas. Nos animais, as quantidades dos elementos figurados do sangue podem ser alteradas por diversos fatores, tais como: idade, condições fisiológica e sanitária, ocorrência de desordens clínicas, condições de estresse, temperatura ambiental e nutrição (FELDMAN; ZINKL; JAIN, 2000). Especialmente nos suínos, o estresse provocado por ocasião do desmame estimula respostas fisiológicas e metabólicas, que podem alterar o quadro eritroleucométrico, trombométrico e seu padrão seroproteico (BUDIÑO et al., 2004).

A ingestão adequada de ração, bem como a utilização de promotores de crescimento (probióticos) ou nutrientes específicos fornecidos através da alimentação dos leitões, pode possibilitar a manutenção da capacidade de digestão e absorção do epitélio intestinal, assim como melhorar o sistema imune do animal (CHESSON, 1994).

Objetivou-se avaliar o eritroleucograma, trombograma e teores das proteínas séricas de leitões recém desmamados, assim como determinar a digestibilidade das rações, contendo ou não probiótico, para suínos em crescimento.

\section{Material e Métodos}

\section{Ensaio 1: Parâmetros sanguíneos}

Foi conduzido na Unidade de Creche do Setor de Suinocultura, do Departamento de Zootecnia e as análises sanguíneas foram realizadas no Laboratório de Patologia Clínica do Hospital Veterinário, ambos da FCAV-UNESP, Câmpus de Jaboticabal. Foram utilizados 20 leitões machos castrados, de idêntico padrão genético (Duroc x Landrace/Large White), desmamados aos 21 dias de idade, com peso corporal de $6,99 \pm 0,42 \mathrm{~kg}$. Os animais foram alojados em quatro baias de $2,71 \mathrm{~m}^{2}$ cada, sendo 
equipadas com aquecedores elétricos, bebedouros tipo chupeta e comedouros tipo cocho.

Utilizou-se o delineamento em blocos casualizados, de acordo com o peso inicial, em esquema fatorial 2 x 5 (duas rações x cinco idades) e para a análise de variância dos dados utilizou-se o programa estatístico (SAS, 1998).

As rações foram formuladas contendo principalmente milho, farelo de soja e produto lácteo (Tabela 1), com o intuito de atender as exigências nutricionais mínimas de acordo com as idades dos leitões, sendo baseadas nas recomendações de Rostagno, Albino e Donzele (2005). Resultando em duas rações experimentais: sem $(0 \mathrm{mg} / \mathrm{kg})$ e com $(200 \mathrm{mg} /$ $\mathrm{kg}$ ) probiótico. Utilizou-se probiótico constituído pelas seguintes bactérias e levedura: Bacillus subtilis, Bacillus natto, Bacillus megaterium, Lactobacillus acidophilus, Lactobacillus plantarum, Lactobacillus brevis, Lactobacillus casei, Streptococcus lactis, Streptococcus faecalis, Streptococcus termophilus e Saccharomyces cerevisiae. Durante o experimento os animais receberam ração e água à vontade e iguais condições de manejo.

Tabela 1. Composições centesimal e nutricional das rações Inicial 1 e 2 (Ensaio 1) fornecidas aos leitões dos 21 aos 35 e dos 36 aos 49 dias de idade, respectivamente, e de crescimento (Ensaio 2).

\begin{tabular}{llll}
\hline \multirow{2}{*}{ Ingredientes (\%) } & \multicolumn{2}{c}{ Rações } \\
\cline { 2 - 4 } & Inicial 1 & Inicial 2 & Crescimento \\
\hline Milho & 66,210 & 67,530 & 73,900 \\
Farelo de soja & 17,570 & 21,260 & 23,150 \\
Leite em pó desnatado & 5,160 & 6,000 & - \\
Proteína isolada de soja & 5,000 & - & 0,240 \\
Óleo de soja & - & - & 1,270 \\
Fosfato bicálcico & 1,350 & 1,070 & 0,630 \\
Calcário calcítico & 0,770 & 0,680 & - \\
Açúcar & 3,000 & 2,740 & 0,410 \\
Sal comum & 0,330 & 0,250 & $0,100^{2}$ \\
Suplemento mineral e vit. & $0,100^{1}$ & $0,100^{1}$ & 0,220 \\
L-Lisina. HCl (78,4\%) & 0,370 & 0,320 & 0,036 \\
DL-Metionina (99,0\%) & 0,090 & 0,040 & 0,031 \\
L-Treonina (98\%) & 0,050 & 0,010 & 0,010 \\
Antioxidante & - & - & 3230 \\
Valores calculados & & & 16,82 \\
Energia metabolizável (kcal/kg) & 3.265 & 3.265 & 0,90 \\
Proteína bruta (\%) & 19,33 & 17,23 & 0,23 \\
Lisina total (\%) & 1,35 & 1,15 & 0,60 \\
Metionina total (\%) & 0,35 & 0,30 & 0,63 \\
Treonina total (\%) & 0,86 & 0,74 & 0,33 \\
Cálcio (\%) & 0,80 & 0,70 & 0,32 \\
Fósforo disponível (\%) & 0,40 & & \\
\hline
\end{tabular}

${ }^{1} \mathrm{O}$ suplemento mineral e vitamínico não continha qualquer tipo de promotor de crescimento ou antibiótico. Concentrações por kg

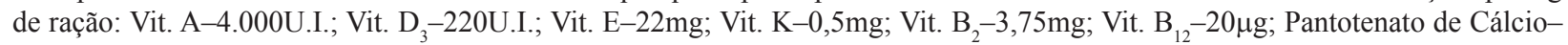

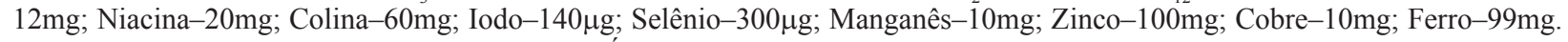
${ }^{2}$ Concentrações de garantia por kg do produto: Ácido fólico-500mg; Selênio-150mg; Cobre-10000mg; Pantotenato de cálcio15000mg; Biotina-100mg; Manganês-23000mg; Iodo-400mg; Niacina-20000mg; Antioxidante-100mg; Vitamina A-6000000UI; Vitamina B1-1257mg; Vitamina B12-15000mcg; Vitamina B2-3336mg; Vitamina B6-1257mg; Vitamina D3-1500000UI; Vitamina E-13000mg; Vitamina K-2000mg e Zinco-80000mg; ${ }^{3}$ As composições das rações experimentais foram calculadas segundo Rostagno, Albino e Donzele (2005).

Fonte: Elaboração dos autores. 
Para o monitoramento do quadro sanguíneo foram colhidas amostras de dois $\mathrm{mL}$ de sangue (EDTA - 1mg/mL sangue), por punção do sinus orbital dos leitões aos 0, 7, 14, 21 e 28 dias pósdesmame, para determinação das concentrações de hemácias $\left(\mathrm{mm}^{3} \times 10^{3}\right)$, hemoglobina $(\mathrm{g} \%)$, hematócrito $(\%)$, leucócitos $-\left(\mathrm{mm}^{3}\right)$ e contagem diferencial de leucócitos, calculando-se as porcentagens de: eosinófilos, neutrófilos bastonetes (jovens), neutrófilos segmentados (maduros), linfócitos, monócitos e a contagem de plaquetas.

Para determinar o teor de proteínas séricas, foram colhidas amostras de quatro $\mathrm{mL}$ de sangue (sem anticoagulante), nos mesmos dias pósdesmame. Foram analisadas, as proteínas séricas totais (método do biureto), albumina (método do verde bromocresol) e eletroforese convencional das frações proteicas. A eletroforese convencional do soro sanguíneo separa, normalmente, a albumina e frações de alfa, beta e gama-globulinas. Nos suínos, as frações beta e gama dificilmente separam-se, formando uma fração única (beta + gama) sendo analisadas desta forma (KANEKO, 1989). O fracionamento eletroforético das proteínas do soro foi realizado de acordo com o procedimento descrito por Sevelius e Andersson (1995).

\section{Ensaio 2: Digestibilidade das rações}

Foi conduzido na Unidade de Digestibilidade do Setor de Suinocultura do Departamento de Zootecnia da FCAV-UNESP, Câmpus de Jaboticabal. Foram utilizadas gaiolas para estudos de metabolismo, semelhantes às descritas por Pekas (1968).

Com a finalidade de que os microrganismos do probiótico colonizassem o trato digestório dos suínos, 23 dias antes de iniciar o ensaio, oito suínos machos castrados da linhagem genética Topigs ${ }^{\circledR}$, com $20,23 \pm 1,65 \mathrm{~kg}$ de peso médio, foram alojados em duas baias, sendo que quatro receberam a ração sem probiótico e quatro a ração com probiótico. Após este período, os animais foram transferidos para as gaiolas, onde receberam as mesmas rações.
Os animais foram distribuídos no delineamento em blocos casualizados, para controlar o peso inicial, com dois tratamentos e quatro repetições, sendo a unidade experimental representada por um animal. A análise de variância foi realizada através do procedimento GLM do SAS (SAS ${ }^{\circledR}$ Institute, 1998), com as médias dos tratamentos comparadas pelo teste de Tukey (5\%).

Foi formulada uma ração a base de milho e farelo de soja (Tabela 1) para atender as exigências mínimas nutricionais dos animais segundo Rostagno, Albino e Donzele (2005). Os tratamentos testados foram os mesmos utilizados no Ensaio 1 - ração sem (0mg/ $\mathrm{kg})$ e com $(200 \mathrm{mg} / \mathrm{kg})$ probiótico.

Utilizou-se o método da colheita total de fezes, com o óxido férrico como marcador fecal na proporção de $1 \%$. Os animais permaneceram nas gaiolas pelo período de 12 dias, sendo os sete primeiros para adaptação às gaiolas e os cinco dias restantes para a colheita de fezes e urina. A quantidade de ração fornecida durante o período de colheita foi de $2 \%$ do peso corporal do animal,

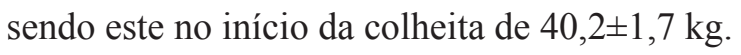

Rações e fezes foram analisadas quanto a: matéria seca (MS), proteína bruta (PB), fibras em detergente neutro (FDN) e ácido (FDA), matéria mineral (MM), segundo Silva e Queiróz (2002), e energia bruta (EB), em bomba calorimétrica do tipo Parr. Na urina determinou-se o nitrogênio (SILVA; QUEIRÓZ, 2002) e a energia bruta. Os cálculos do coeficiente de digestibilidade da energia, dos nutrientes e de metabolizabilidade da energia foram realizados segundo Adeola (2001).

\section{Resultados e Discussão}

\section{Parâmetros sanguíneos}

Observou-se efeito (Tabela 2) da adição do probiótico sobre os valores de hemoglobina, hematócrito e plaquetas, que foram maiores $(\mathrm{P}<0,05)$ nos animais que consumiram ração com probiótico. Já os valores de leucócitos foram 
maiores $(\mathrm{P}<0,05)$ naqueles que receberam a ração sem probiótico. A trombocitopenia desenvolvese como resultado da diminuição do número de plaquetas sobreviventes ou do decréscimo na sua produção. Ambos os processos podem ocorrer nos animais que têm infecções bacterianas. A redução das plaquetas no sangue foi reconhecida como a anormalidade hematológica mais comum em animais que apresentam infecções causadas por Escherichia coli (STOCKHAM, 2000). Desta forma pode-se inferir que os animais que tiveram acesso ao probiótico apresentaram uma condição plaquetária melhor por estarem provavelmente menos expostos a patógenos (BUDIÑO et al, 2004).

Tabela 2. Médias das características eritroleucométricas e trombométricas ${ }^{1}$ dos leitões, em função da ração e do número de dias pós desmame.

\begin{tabular}{lllllllllll}
\hline Fatores $^{2}$ & $\mathrm{He}$ & $\mathrm{Le}$ & $\mathrm{Hb}$ & $\mathrm{Ht}$ & $\begin{array}{l}\text { Eos } \\
\%\end{array}$ & $\begin{array}{l}\text { NBast } \\
\%\end{array}$ & $\begin{array}{l}\mathrm{NSeg} \\
\%\end{array}$ & $\begin{array}{l}\text { Linf } \\
\%\end{array}$ & $\begin{array}{l}\text { Mon } \\
\%\end{array}$ & $\begin{array}{l}\text { Plaq } \\
\mu \mathrm{L}\end{array}$ \\
\hline Ração & $\mathrm{P}=0,44$ & $\mathrm{P}=0,001$ & $\mathrm{P}=0,035$ & $\mathrm{P}=0,017$ & $\mathrm{P}=0,86$ & $\mathrm{P}=0,20$ & $\mathrm{P}=0,130$ & $\mathrm{P}=0,22$ & $\mathrm{P}=0,97$ & $\mathrm{P}=0,002$ \\
Idade & $\mathrm{P}=0,001$ & $\mathrm{P}=0,001$ & $\mathrm{P}=0,001$ & $\mathrm{P}=0,001$ & $\mathrm{P}=0,001$ & $\mathrm{P}=0,001$ & $\mathrm{P}=0,001$ & $\mathrm{P}=0,001$ & $\mathrm{P}=0,001$ & $\mathrm{P}=0,001$ \\
Interação & $\mathrm{P}=0,74$ & $\mathrm{P}=0,13$ & $\mathrm{P}=0,87$ & $\mathrm{P}=0,89$ & $\mathrm{P}=0,81$ & $\mathrm{P}=0,37$ & $\mathrm{P}=0,90$ & $\mathrm{P}=0,86$ & $\mathrm{P}=0,93$ & $\mathrm{P}=0,540$ \\
$\mathrm{CV}(\%)^{3}$ & 7,65 & 21,26 & 8,4 & 8,67 & 24,24 & 26,13 & 21,94 & 23,83 & 28,33 & 25,00 \\
\hline Ração $^{4}$ & & & & & & & & & & \\
$\mathrm{SP}$ & 6614 & $16456^{\mathrm{a}}$ & $11,84^{\mathrm{b}}$ & $38,04^{\mathrm{b}}$ & 1,06 & 1,5 & 50,14 & 44,5 & 2,72 & $425280^{\mathrm{b}}$ \\
$\mathrm{CP}$ & 6749 & $14080^{\mathrm{b}}$ & $12,32^{\mathrm{a}}$ & $39,41^{\mathrm{a}}$ & 1,1 & 1,44 & 47,7 & 47 & 2,74 & $477780^{\mathrm{a}}$ \\
\hline $\mathrm{Idade}^{5}$ & & & & & & & & & & \\
0 & $5922^{\mathrm{c}}$ & $9105^{\mathrm{d}}$ & $11,29^{\mathrm{c}}$ & $37,44^{\mathrm{b}}$ & $2,05^{\mathrm{a}}$ & $0,45^{\mathrm{b}}$ & $48,70^{\mathrm{b}}$ & $45,15^{\mathrm{b}}$ & $3,20^{\mathrm{a}}$ & $595700^{\mathrm{a}}$ \\
7 & $7086^{\mathrm{a}}$ & $12430^{\mathrm{c}}$ & $12,94^{\mathrm{a}}$ & $41,90^{\mathrm{a}}$ & $0,90^{\mathrm{b}}$ & $1,50^{\mathrm{ab}}$ & $45,90^{\mathrm{bc}}$ & $46,70^{\mathrm{b}}$ & $4,75^{\mathrm{a}}$ & $418750^{\mathrm{b}}$ \\
14 & $7134^{\mathrm{a}}$ & $19395^{\mathrm{a}}$ & $12,70^{\mathrm{ab}}$ & $40,52^{\mathrm{a}}$ & $0,55^{\mathrm{b}}$ & $0,80^{\mathrm{b}}$ & $61,40^{\mathrm{a}}$ & $33,50^{\mathrm{c}}$ & $3,50^{\mathrm{a}}$ & $410950^{\mathrm{b}}$ \\
21 & $6689^{\mathrm{ab}}$ & $19335^{\mathrm{a}}$ & $11,91^{\mathrm{bc}}$ & $36,97^{\mathrm{b}}$ & $1,05^{\mathrm{b}}$ & $2,00^{\mathrm{ab}}$ & $50,10^{\mathrm{b}}$ & $45,90^{\mathrm{b}}$ & $0,95^{\mathrm{b}}$ & $455250^{\mathrm{b}}$ \\
28 & $6572^{\mathrm{b}}$ & $16075^{\mathrm{b}}$ & $11,57^{\mathrm{c}}$ & $36,82^{\mathrm{b}}$ & $0,85^{\mathrm{b}}$ & $2,60^{\mathrm{a}}$ & $38,50^{\mathrm{c}}$ & $56,50^{\mathrm{a}}$ & $1,25^{\mathrm{b}}$ & $377000^{\mathrm{b}}$ \\
\hline
\end{tabular}

${ }^{1} \mathrm{He}=$ hemácia, $\mathrm{Le}=$ leucócito, $\mathrm{Hb}=$ hemoglobina, $\mathrm{Ht}=$ hematócrito, $\mathrm{Eos}=$ eosinófilo, $\mathrm{NBast}=$ neutrófilo bastonete, $\mathrm{NSeg}=$ neutrófilo segmentado, Linf = linfócito, Mon = monócito; Plaquetas = Plaq;

${ }^{2}$ Não houve interação significativa entre os fatores;

${ }^{3}$ Coeficiente de variação;

${ }^{4}$ SP-ração sem probiótico e CP-ração com probiótico;

${ }^{5}$ Idade: dias pós-desmame;

abc Médias seguidas da mesma letra em cada coluna não diferem entre si pelo teste de Tukey (P>0,05). As variáveis Eos, NBast e Mon foram transformados pela equação $(\mathrm{Y}+1)^{1 / 2}$.

Fonte: Elaboração dos autores.

A quantidade de linfócitos no sangue dos suínos alimentados com ração contendo probiótico foi 5,6\% maior $(\mathrm{P}>0,05)$ comparada à daqueles que consumiram ração sem o produto. Maiores concentrações de linfócitos no sangue de leitões, alimentados com probiótico podem ser relacionadas aos desafios submetidos aos animais no período experimental, nos quais ocorre a liberação do hormônio corticotrófico (ACTH) que determina a redução da quantidade de linfócitos circulantes (MACARI; LUQUETTI,
2002). Perdigon et al. (1986) também observaram alterações imunológicas quando administraram $L$. acidophilus e $S$. thermophilus para camundongos, relatando ativação na atividade de macrófagos e linfócitos nestes animais.

Quanto às idades, os valores de hemácias, leucócitos, hemoglobina e hematócrito aumentaram $(\mathrm{P}<0,05)$ na primeira semana após o desmame, mantendo-se até a segunda. Os leucócitos aumentaram linearmente até a terceira semana pós- 
desmame. No caso das hemácias, hemoglobina e hematócrito, tais modificações podem ser devido à liberação de catecolaminas (adrenalina e noradrenalina), causando aumento na pressão sanguínea e contração esplênica, que redunda em uma descarga de hemácias na corrente circulatória (SWENSON, 1996). Além disso, a adrenalina liberada em resposta à excitação ou estresse, mobiliza as células leucocitárias marginais para a circulação, o que concorre também para o aumento na contagem total dos leucócitos quando o animal está estressado (FELDMAN; ZINKL; JAIN, 2000).

Os valores de linfócitos foram mantidos constantes $(\mathrm{P}>0,05)$ nos dias 0 e 7 após o desmame. Porém, no dia 14 reduziram-se significativamente, voltando a aumentar $(\mathrm{P}<0,05)$ e atingindo valores máximos no dia 28 pós-desmame. Estes resultados podem ser explicados devido à grande redução na quantidade de linfócitos circulantes quando o animal é submetido a situações de estresse, que migram para regiões afetadas do organismo como mucosas, intestinos, útero e pulmões (SWENSON, 1996).

As variações ocorridas nos valores dos parâmetros sanguíneos, com o aumento da idade dos animais, estão de acordo com os dados reportados por Budiño et al. (2004). Os valores de eosinófilos e plaquetas diminuíram $(\mathrm{P}<0,05)$ aos 7, 14, 21 e 28 dias pós-desmame em comparação ao dia 0 . Estes resultados podem ser explicados devido à função primordial dos eosinófilos, que é de detoxificação do organismo e estão presentes em maior concentração nos locais onde ocorrem reações antígeno-anticorpo e nos pontos de penetração de substâncias estranhas ao organismo, bem como em menor quantidade na corrente circulatória em situações de estresse, reaparecendo no período de recuperação (FELDMAN; ZINKL; JAIN, 2000).

As proteínas séricas totais, a albumina e alfa globulinas (Tabela 3) não foram $(\mathrm{P}>0,05)$ afetadas pelas rações com ou sem probiótico. Os animais que consumiram ração sem probiótico apresentaram maiores $(\mathrm{P}<0,05)$ teores de globulina e beta + gama globulinas em relação aos que receberam a ração com probiótico. As concentrações de beta globulinas tendem a aumentar com a ocorrência de doenças inflamatórias e as de gama globulinas com doenças infecciosas (KANEKO, 1989).

Tabela 3. Médias e erros padrão das médias de proteínas séricas totais, albumina, globulinas e alfa e beta + gama globulinas no sangue de leitões em função das dietas e do número de dias pós-desmame.

\begin{tabular}{llllll}
\hline \multirow{2}{*}{ Fatores } & \multicolumn{5}{c}{ Proteínas séricas } \\
\cline { 2 - 6 } & Totais g/dL & Albumina g/dL & Globulina g/dL & Alfa \% & Beta + Gama \% \\
\hline Ração & $\mathrm{P}=0,096$ & $\mathrm{P}=0,52$ & $\mathrm{P}=0,010$ & $\mathrm{P}=0,56$ & $\mathrm{P}=0,030$ \\
Idade & $\mathrm{P}=0,059$ & $\mathrm{P}=0,001$ & $\mathrm{P}=0,001$ & $\mathrm{P}=0,001$ & $\mathrm{P}=0,002$ \\
Interação & $\mathrm{P}=0,056$ & $\mathrm{P}=0,24$ & $\mathrm{P}=0,30$ & $\mathrm{P}=0,40$ & $\mathrm{P}=0,700$ \\
CV (\%) & 6,97 & 9,96 & 16,46 & 13,32 & 13,66 \\
\hline Ração & $5,34 \pm 0,06$ & $2,97 \pm 0,06$ & $2,50 \pm 0,09^{\text {a }}$ & $23,72 \pm 0,45$ & $38,11 \pm 0,76^{\text {a }}$ \\
\hline Sem probiótico & $5,23 \pm 0,05$ & $3,05 \pm 0,06$ & $2,18 \pm 0,06^{\mathrm{b}}$ & $24,36 \pm 0,56$ & $35,87 \pm 0,76^{\mathrm{b}}$ \\
Com probiótico & $5,28 \pm 0,06$ & $3,59 \pm 0,05^{\mathrm{a}}$ & $1,69 \pm 0,03^{\mathrm{c}}$ & $21,53 \pm 0,71^{\mathrm{b}}$ & $33,17 \pm 0,76^{\mathrm{b}}$ \\
\hline Idade: dias pós- desmame & $5,19 \pm 0,06$ & $3,06 \pm 0,05^{\mathrm{b}}$ & $2,13 \pm 0,06^{\mathrm{bc}}$ & $24,64 \pm 0,78^{\text {ab }}$ & $38,16 \pm 1,26^{\mathrm{a}}$ \\
\hline 0 & $4,99 \pm 0,11$ & $2,76 \pm 0,09^{\mathrm{b}}$ & $2,54 \pm 0,08^{\mathrm{ab}}$ & $26,05 \pm 0,80^{\mathrm{a}}$ & $36,66 \pm 1,25^{\text {ab }}$ \\
7 & $5,36 \pm 0,11$ & $2,75 \pm 0,07^{\mathrm{b}}$ & $2,61 \pm 0,07^{\mathrm{ab}}$ & $23,40 \pm 0,56^{\text {ab }}$ & $39,76 \pm 1,44^{\mathrm{a}}$ \\
14 & $5,62 \pm 0,07$ & $2,90 \pm 0,07^{\mathrm{b}}$ & $2,72 \pm 0,09^{\mathrm{a}}$ & $24,58 \pm 0,68^{\text {ab }}$ & $37,24 \pm 0,85^{\text {ab }}$ \\
\hline
\end{tabular}

${ }^{\mathrm{ab}}$ Médias seguidas da mesma letra em cada coluna não diferem entre si pelo teste de Tukey $(\mathrm{P}>0,05)$;

CV - Coeficiente de variação.

Fonte: Elaboração dos autores. 
Com relação à idade, todos os parâmetros estudados foram afetados $(\mathrm{P}<0,05)$, com exceção das proteínas séricas totais. No caso da albumina, o valor observado no dia 0 , foi maior $(\mathrm{P}<0,05)$ em relação aos demais dias de colheita, os quais não apresentaram diferença $(\mathrm{P}>0,05)$, o que concordou com os achados de Kaneko (1989). Os valores observados para globulina aumentaram gradativamente com a idade, enquanto que a alfa globulina teve seu menor valor $(\mathrm{P}<0,05)$ no dia 0 e o maior $(\mathrm{P}<0,05)$ aos 14 dias pós-desmame. Os maiores $(\mathrm{P}<0,05)$ valores de beta + gama globulinas foram observados nos dias 7 e 21 pós-desmame e o menor $(\mathrm{P}<0,05)$ no dia do desmame. Os valores de todas as frações apresentaram-se normais quando comparados àqueles obtidos por Kaneko (1989) e Budiño et al. (2004).

Os probióticos podem possuir ação na imunomodulação do hospedeiro, devido à produção de glicopeptídeos ou outros metabólitos (CHESSON, 1994). Alguns gêneros de bactérias intestinais como Lactobacillus e Bifidobacterium estão diretamente relacionados com o aumento da resposta imune, produção de anticorpos, ativação de macrófagos, proliferação de células $\mathrm{T}$ e produção de interferon (MENTEN, 2001). Pesquisas demonstraram que o número de leucócitos no sangue e a concentração plasmática de IgG de leitões desmamados aumentaram após a administração de Lactobacillus acidophilus (CHESSON, 1994).

\section{Digestibilidade das rações}

Os coeficientes de digestibilidade e de metabolizabilidade, os nutrientes digestíveis e as energias digestível e metabolizável das rações (Tabela 4) foram semelhantes $(\mathrm{P}>0,05)$ para os tratamentos estudados, com exceção da matéria mineral, que foi mais $(\mathrm{P}<0,06)$ absorvida nos animais que consumiram ração contendo o probiótico. Tais resultados discordaram dos encontrados por Kornegay e Risley (1996), que observaram melhorias nas digestibilidades da matéria seca e da proteína bruta, avaliadas em suínos em terminação, recebendo rações contendo Bacillus spp, comparados àqueles sem suplementação do probiótico. No entanto, no caso da matéria mineral absorvida a melhoria foi de apenas $1,70 \%$, o que discordou dos dados obtidos no presente estudo, cuja diferença foi de $7,83 \%$, em favor dos animais suplementados com probiótico. Estes resultados concordaram com os obtidos anteriormente por Huaynate et al. (2006), os quais observaram menores excreções de minerais nas fezes de suínos nas fases inicial e de crescimento, quando receberam probiótico nas rações.

Quanto à proteína, os resultados obtidos neste experimento, discordaram daqueles observados por Silveira et al. (2007), que notaram maior coeficiente de digestibilidade deste nutriente em suínos que receberam probiótico nas dietas.

Embora sem apresentar resultados significativos, os animais que receberam probiótico na ração, digeriram melhor os nutrientes da dieta em relação aos demais, demonstrando que o produto pode ter auxiliado na digestão e/ou na absorção desses nutrientes, o que confirma as observações de Leedle (2000), os quais afirmaram que certas espécies de microrganismos presentes em probióticos secretam amilase, protease e lipase, que podem favorecer a digestão do alimento. 
Tabela 4. Coeficientes de digestibilidade (CDA) e de metabolizabilidade (CMA) aparentes e valores nutricionais das rações de suínos em crescimento suplementadas ou não com probiótico.

\begin{tabular}{llllll}
\hline \multicolumn{1}{c}{ Variável } & Sem probiótico & Com probiótico & $\mathrm{P}$ & ${\text { Dif. }(\%)^{1}}^{\text {CV }(\%)^{2}}$ \\
\hline CDA Matéria seca, \% & 87,19 & 88,52 & 0,37 & $+1,33$ & 2,21 \\
CDA Energia bruta, \% & 86,68 & 88,22 & 0,34 & $+1,54$ & 2,39 \\
CMA Energia bruta, \% & 83,98 & 85,71 & 0,42 & $+1,73$ & 3,33 \\
CDA Proteína bruta, \% & 85,35 & 88,34 & 0,16 & $+2,99$ & 3,05 \\
CDA FDN $^{3}, \%$ & 80,68 & 83,27 & 0,47 & $+2,59$ & 5,72 \\
CDA FDA $^{3}, \%$ & 70,45 & 73,43 & 0,68 & $+2,98$ & 13,17 \\
Matéria mineral absorvida, \% & 50,28 & 58,11 & 0,06 & $+7,83$ & 8,78 \\
Energia digestível, kcal/kg & 3.445 & 3.503 & & & \\
Energia metabolizável, kcal/kg & 3.337 & 3.403 & & & \\
Proteína digestível, \% & 15,56 & 16,44 & & & \\
FDN digestível, \% & 17,09 & 18,43 & & & \\
FDA digestível, \% & 3,64 & 4,07 & & & \\
Matéria mineral retida, \% & 1,99 & 2,50 & & & \\
Matéria seca digestível, \% & 77,22 & 78,44 & & & \\
\hline
\end{tabular}

${ }^{1}$ Diferença entre as rações com e sem probiótico, em unidades percentuais;

${ }^{2}$ Coeficientes de variação;

${ }^{3}$ Fibra em Detergente Neutro e Fibra em Detergente Ácido.

Fonte: Elaboração dos autores.

\section{Conclusões}

A adição de probiótico às rações de leitões recém desmamados diminuiu as quantidades de leucócitos e aumentou a hemoglobina, o hematócrito, as plaquetas e a síntese de globulinas e beta+gama globulinas. A idade dos animais afetou todas as variáveis sanguíneas analisadas, com exceção da proteína sérica total. A inclusão do probiótico nas dietas de suínos em crescimento melhorou em 7,83\% a absorção da matéria mineral.

\section{Referências}

ADEOLA, O. Digestion and balance techniques in pigs. In: LEWIS, A. J.; SOUTHERN, L. L. Swine nutrition. (Ed.). New York: Boca Raton London, 2001. p. 903-916.

BUDIÑO, F. E. L.; THOMAZ, M. C.; KRONKA, R. N.; JUNIOR, J. M. P.; SANTANA, A. E.; TUCCI, F. M.; FRAGA, A. L.; SCANDOLERA, A. J.; ROBLESHUAYNATE, R. A. Influência da adição de probiótico e/ou prebiótico em dietas de leitões desmamados sobre as atividades das enzimas digestivas e parâmetros sangüíneos. Acta Scientiarum Animal Science, Maringá, v. 26, n. 4, p. 529-536, 2004.
CHESSON, A. Probiotics and other intestinal mediators. In: COLE, D. J. A.; WISEMAN, J.; VARLEY, M. A. Principles of pig science. Nottingham: Nottingham University Press, 1994. p. 197-214.

FELDMAN, B. F.; ZINKL, J. G.; JAIN, N. C. Schalm's veterinary hematology. 5. ed. Philadelphia: Lippincott, Williams \& Wilkins, 2000. 1344 p.

HUAYNATE, R. A. R.; THOMAZ, M. C.; KRONKA, R. N.; FRAGA, A. L.; SCANDOLERA, A. J.; BUDIÑO, F. E. L. Effect of adding macro and micro minerals in pigs feces fed diets with different levels of probiotic. Brazilian Archives Biology Technology, Curitiba, v. 49, n. 3, p. 385-392, 2006.

KANEKO, J. J. Clinical biochemistry of domestic animals. $4^{\text {td }}$ ed. California: Academic Press, 1989. 932 p.

KORNEGAY, E. T.; RISLEY, C. R. Nutrient digestibilities of a corn-soybean meal diet as influenced by Bacillus products fed to finishing swine. Journal Animal Science, Champaign, v. 74, n. 4, p. 799-805, 1996.

LAN, Y.; VERSTEGEN, M. W. A.; TAMMINGA, S.; WILLIAMS, B. A. The role of the commensal gut microbial community in broiler chickens. World's Poultry Science Journal, Beekbergen, v. 61, n. 1, p. 95104, 2005.

LEEDLE, J. Probiotics and DFMs - mode of action in the gastrointestinal tract. In: SIMPÓSIO SOBRE ADITIVOS 
ALTERNATIVOS NA NUTRIÇÃO ANIMAL, 2000, Campinas. Anais... Campinas: Colégio Brasileiro de Nutrição Animal, 2000. p. 25-40.

MACARI, M.; LUQUETTI, B. C. Fisiologia cardiovascular. In: MACARI, M.; FURLAN, R. L.; GONZÁLES, E. (Ed.). Fisiologia aviária aplicada a frangos de corte. Jaboticabal: FUNEP, 2002. p. 17-36.

MENTEN, J. F. M. Aditivos alternativos na nutrição de aves: probióticos e prebióticos. In: REUNIÃO ANUAL DA SOCIEDADE BRASILEIRA DE ZOOTECNIA, 38., 2001, Piracicaba. Anais... Piracicaba: SBZ, 2001. p. 141-157.

MONTAGNE, L.; PLUSQUE, J. R.; HAMPSON, D. J. A review of interactions between dietary fibre and the intestinal mucosa, and their consequences on digestive health in young non-ruminant animals. Animal Feed Science Technology, Philadelphia, v. 108, n. 1-4, p. 95117, 2003.

PEKAS, J. C. Versatible swine laboratory apparatus for physiologic and metabolic studies. Journal Animal Science, Champaign, v. 27, n. 5, p. 1303-1309, 1968.

PERDIGON, G.; NADER DE MACIAS, M. E.; ALVAREZ, S.; OLIVER, G.; PESCE DE RUIZ HOLGADO, A. Enhancement of immune response in mice fed with Streptococcus thermophilus and Lactobacillus acidophilus. Journal Dairy Science, Champaign, v. 70, n. 5, p. 919-926, 1986.

ROSTAGNO, H. S.; ALBINO, L. F. T.; DONZELE, J. L. Tabelas brasileiras para aves e suínos composição de alimentos e exigências nutricionais de aves e suínos. Viçosa: UFV, 2005. 186 p.
SEVELIUS, E.; ANDERSSON, M. Serum protein eletrophoresis as a prognostic marker of chronic liver disease in dogs. Veterinary Record, London, v. 137, n. 26, p. 663-667, 1995.

SILVA, D. J.; QUEIRÓZ, A. C. Análise de alimentos: métodos químicos e biológicos. 2. ed. Viçosa: UFV, 2002. $235 \mathrm{p}$.

SILVEIRA, H.; BARBOSA, C. E. T.; ALMEIDA, E. C.; PEREIRA, L. M.; CERQUEIRA, L. G. S.; SOUZA, P. F. A. Utilização de probiótico mais composto enzimático sobre a digestibilidade dos nutrientes e balanço de nitrogênio em leitões. In: CONGRESSO BRASILEIRO DE VETERINÁRIOS ESPECIALISTAS EM SUÍNOS, 13., 2007, Florianópolis. Anais... Florianópolis: ABRAVES, 2007. p. 433-434.

STATISTICAL ANALYSIS SYSTEM INSTITUTE SAS. SAS users guide: statistics. Cary: SAS, 1998. 956 p.

STOCKHAM, S. L. Hematologic changes due to bacterial infections. In: FELDMAN, B. F.; ZINKL, J. G.; JAIN, N. C. Schalm's veterinary hematology. 5. ed. Philadelphia: Lippincott, Williams \& Wilkins, 2000. p. 38-43.

SWENSON, M. J. Propriedades fisiológicas e componentes químicos e celulares do sangue - parte 1. In: SWENSON, M. J.; REECE, W. O. (Ed.). Dukes - fisiologia dos animais domésticos. 11. ed. Guanabara, 1996. p. 9-19.

WALKER, W. A.; DUFFY, L. C. Diet and bacterial colonization: role of probiotics and prebiotics. Journal Nutrition, Bethesda, v. 9, n. 12, p. 668-675, 1998. 
